\begin{abstract}
Iranica
Abstracta Iranica Revue bibliographique pour le domaine irano-aryen

Volume 32-33 | 2013

Comptes rendus des publications de 2009-2010
\end{abstract}

\title{
Hormuz Key. Le cinéma iranien: Récit d'une continuité
}

\section{Yoko Suzuki}

\section{OpenEdition}

\section{Journals}

Édition électronique

URL : http://journals.openedition.org/abstractairanica/40161

DOI : 10.4000/abstractairanica.40161

ISSN : 1961-960X

Éditeur :

CNRS (UMR 7528 Mondes iraniens et indiens), Éditions de l'IFRI

\section{Édition imprimée}

Date de publication : 1 décembre 2013

ISSN : 0240-8910

\section{Référence électronique}

Yoko Suzuki, «Hormuz Key. Le cinéma iranien: Récit d'une continuité », Abstracta Iranica [En ligne], Volume 32-33 | 2013, document 471, mis en ligne le 01 juillet 2016, consulté le 05 octobre 2020. URL : http://journals.openedition.org/abstractairanica/40161; DOI : https://doi.org/10.4000/ abstractairanica.40161

Ce document a été généré automatiquement le 5 octobre 2020.

Tous droits réservés 


\title{
Hormuz Key. Le cinéma iranien: Récit d'une continuité
}

\author{
Yoko Suzuki
}

\section{RÉFÉRENCE}

Hormuz Key. « Le cinéma iranien: Récit d'une continuité ». Cinéma et monde musulman : Cultures et interdits, l'Harmattan, 2009, p. 57-90.

1 C'est un article paru d'abord dans l'ouvrage collectif publié par EurOrient en 2001 et réédité par l'éditeur ci-dessus. En somme, il est le résumé de la thèse de doctorat de l'A., intitulée Le cinéma iranien: l'image d'une société en bouillonnement, publiée par Karthala en 1999. Pour cette raison, le mouvement du cinéma après les années 2000, malgré ses progrès éblouissants dans le sens de la qualité et de la diversité, n'est pas concerné par l'article.

2 Notant la progression cinématographique iranienne dans les années 1990 grâce à une augmentation du budget gouvernemental, l'A. révèle une continuité des tendances des films iraniens entre deux époques, prérévolutionnaire et postrévolutionnaire: des cinéastes, ayant appris par l'expérience avant la révolution islamique se sont dirigés vers la voie humaniste passés par la critique politique contre le régime: Bahman Beyḍ̂à̄ et Parvīz Kīmiyāvī, entre autres, se sont servis du cinéma pour contester la politique du Chah, puis Mas'ūd Kīmiyāyī et Dāriyūš Mehrjūyī ont été critiques envers ce régime, et ont développé une perspective sociale, dès la fin des années 1960 ; au début des années 1970, Sohrāb Šahīd Tâalet a intériorisé cette vision pour montrer la société à travers des images de ceux qui la constituent, à savoir des êtres humains dans la vie quotidienne. 'Abbās Kiyārostamī qui est sur la même voie que Tāleț, selon l'A., se focalise sur la vie des personnes ordinaires et sur leurs forces tranquilles.

Avec sa belle écriture, cet article nous présente un bon résumé de l'histoire du cinéma iranien. Pourtant, grâce à son regard de sociologue, l'A. pourrait nous présenter non seulement des films "artistiques» mais aussi des films comiques ou humoristiques, 
très populaires et traditionnels en Iran, ainsi que les tendances des spectateurs au cours de ces deux époques.

\section{AUTEURS}

YOKO SUZUKI

Paris 